\title{
PDGFR $\alpha$ depletion attenuates glioblastoma stem cells features by modulation of STAT3, RB1 and multiple oncogenic signals
}

\author{
Carlo Cenciarelli ${ }^{1}$, Hany E. Marei ${ }^{2}$, Armando Felsani ${ }^{3}$, Patrizia Casalbore ${ }^{3}$, Gigliola \\ Sica $^{4}$, Maria Ausiliatrice Puglisi ${ }^{5}$, Angus J.M. Cameron ${ }^{6}$, Alessandro Olivi7, \\ Annunziato Mangiola ${ }^{7}$ \\ ${ }^{1}$ Institute of Translational Pharmacology, Department of Biomedical Sciences-National Research Council (IFT-CNR), Rome, Italy \\ ${ }^{2}$ Biomedical Research Center, Qatar University, Doha, Qatar \\ ${ }^{3}$ Institute of Cell Biology and Neurobiology, Dept. of Biomedical Sciences-National Research Council (IBCN-CNR), Rome, Italy \\ ${ }^{4}$ Institute of Histology and Embryology, Catholic University-School of Medicine, Rome, Italy \\ ${ }^{5}$ Department of Internal Medicine and Gastroenterology, Agostino Gemelli Hospital, Rome, Italy \\ ${ }^{6}$ Barts Cancer Institute, John Vane Science Centre, Queen Mary University of London, London, United Kingdom \\ ${ }^{7}$ Institute of Neurosurgery, Department of Head and Neck, Catholic University-School of Medicine, Rome, Italy \\ Correspondence to: Carlo Cenciarelli, email: carlo.cenciarelli@ift.cnr.it \\ Keywords: glioblastoma, cancer stem cells, PDGFRa, STAT3, RB 1 \\ Received: April 05, $2016 \quad$ Accepted: June 09, $2016 \quad$ Published: June 17, 2016
}

\section{ABSTRACT}

Platelet derived growth factor receptors (PDGFRs) play an important role in tumor pathogenesis, and they are frequently overexpressed in glioblastoma (GBM). Earlier we have shown a higher protein expression of PDGFR isoforms ( $\alpha$ and $\beta$ ) in peritumoral-tissue derived cancer stem cells ( $p$-CSC) than in tumor core (c-CSC) of several GBM affected patients. In the current study, in order to assess the activity of PDGFR $\alpha$ /PDGF-AA signaling axis, we performed time course experiments to monitor the effects of exogenous PDGF-AA on the expression of downstream target genes in c-CSC vs p-CSC. Interestingly, in p-CSC we detected the upregulation of Y705phosphorylated Stat3, concurrent with a decrement of Rb1 protein in its active state, within minutes of PDGF-AA addition. This finding prompted us to elucidate the role of PDGFRa in self-renewal, invasion and differentiation in p-CSC by using short hairpin RNA depletion of PDGFRa expression. Notably, in PDGFRa-depleted cells, protein analysis revealed attenuation of stemness-related and glial markers expression, alongside early activation of the neuronal marker MAP2a/b that correlated with the induction of tumor suppressor $R \mathbf{B b} 1$. The in vitro reduction of the invasive capacity of PDGFR $\alpha$-depleted CSC as compared to parental cells correlated with the downmodulation of markers of epithelial-mesenchymal transition phenotype and angiogenesis. Surprisingly, we observed the induction of anti-apoptotic proteins and compensatory oncogenic signals such as EDN1, EDNRB, PRKCB1, PDGF-C and PDGF-D. To conclude, we hypothesize that the newly discovered PDGFRa/Stat3/Rb1 regulatory axis might represent a potential therapeutic target for GBM treatment.

\section{INTRODUCTION}

Among the different types of adult brain tumors, glioblastoma multiforme (GBM) is the most aggressive and angiogenic, but despite the efforts to find effective treatments, these tumors remain incurable [1]. The amplification and/or overexpression of either EGFR or PDGFR can contribute to the malignant phenotype of distinct subsets of human glioblastoma [2]. More recently, a classification of GBM in subclasses has been defined for the selection of the best-tailored therapeutic approaches $[3,4]$. Platelet-derived growth factors (PDGFs) isoforms and receptors (PDGFRs) have important functions in the regulation of growth and survival of certain cell types during embryonal development and in control of tissue homeostasis in the adult [5]. A wide range of work from 
in vitro studies to mouse models have implicated the role of the PDGF pathway in cellular invasion and tumor angiogenesis [6]. In fact, over-activity of PDGF signaling is associated with tumor development in brain, prostate, liver, lung, leukemia and colon cancers [7, 8]. Although anti-VEGF treatment has been the major therapeutic target in gliomas, other antiangiogenic agents such as anti-PDGFs or anti-FGFs are currently in preclinical and clinical development [9]. PDGFR includes two receptors $(\alpha$ and $\beta$ ) and four ligands (PDGF-A, PDGF-B, PDGF-C and PDGF-D). The PDGFs bind to the receptors with different affinities. Thus, PDGF-AA, -AB, -BB and -CC induce $\alpha \alpha$ receptor homodimers, PDGF-BB and -DD $\beta \beta$ receptor dimerization, and $\mathrm{PDGF}-\mathrm{AB},-\mathrm{BB},-\mathrm{CC}$ and $-\mathrm{DD}$ $\alpha \beta$ receptor dimerization [5]. Ligand-induced dimerization favors autophosphorylation of specific tyrosine residues and subsequent activates downstream signal pathways: PI3K/Akt1/mTOR, Ras/MAPK, PLC- $\gamma /$ PKC and STAT3. PDGFR binds and activates signal transducers and activator of transcription (STATs). Phosphorylation of Y705 in Stat3 leads to dimerization, nuclear translocation, recognition of Stat3-specific DNA binding elements and up-regulation of various Stat3 downstream target genes, such as Bcl-xl, Bcl-2, Survivin, c-Myc and Cyclin D1. Stat3 regulates tumorigenesis and tumor inflammation and behaves in an oncogenic manner depending on the genetic background of the tumor [1]. In recent studies, Stat3 has been implicated in the self-renewal of neural stem cells and glial differentiation while restricting neuronal differentiation [8-13].

The PKC family consists of fifteen isozymes divided into three subfamilies: conventional (or classical), novel, and atypical. Conventional PKCs contain the isoforms $\alpha$, $\beta$ I, $\beta$ II, and $\gamma$. The PDGFR downstream target PKC $\alpha$ plays an important role in migration, tumor growth, angiogenesis and drug resistance in GBM cells [14-16]. In 1992, PKC $\alpha$ was suggested as marker of malignancy for gliomas, and more recently serum PKC $\alpha$ serves as a biomarker for diagnosis of cancers $[14,15]$. The invasion/migration of GBM cells induced by TPA, occurs through activation of

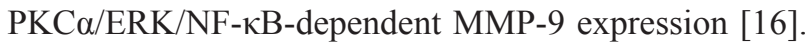
A positive feedback loop between Wnt5A and phosphoPKC in promotion of epithelial-mesenchymal transition (EMT) in nasopharyngeal carcinoma was disclosed [17]. In addition, PDGF receptors bind to other tyrosine kinase receptors, e.g. EGFR [18]. Retinoblastoma 1 (RB1) gene belongs to a family of three proteins, including also RBL1/ p107 and RBL2/p130. Classically the tumor suppressive function of $\mathrm{Rb}$ proteins have been mainly attributed to their ability to arrest cell cycle by repressing E2F target genes. When Rb1 is in its active hypophosphorylated state, it represses E2F-mediated transcription by binding, blocks the E2F transactivation domain, and forms complexes with its (DPs transcription factors) partners at cell cycle gene promoters [19]. Conversely, Rb1 phosphorylation initiated by cyclin D-CDK4/6 in response to mitogenic signals, inactivates the $\mathrm{Rb} 1$ repressive function by dissociating the Rb1-E2F-DP complexes [19]. The Cancer Genome
Atlas Research Network revealed in 2008 that the CycD1CDK4/6-Rb1 pathway is among the top three most altered pathways in GBM, which makes this an appealing target for cancer therapy [20-22].

We and others recently demonstrated that inhibition of either PDGFR $\alpha$ or PDGFR $\beta$ signaling induced apoptosis in glioblastoma stem cells $[23,7]$. In the present study, we aimed to assess the effects of PDGFR $\alpha$ depletion on stemness, invasion and differentiation in GBM CSC. Our findings reveal an inverse correlation between Stat3 Y705phosphorylation and the hypophosphorylated Rb1 instructed by the PDGFR $\alpha /$ PDGF-AA regulatory axis. Further, downmodulation of cell growth, invasion and the EMT phenotype are triggered by PDGFR $\alpha$ depletion in GBM CSC. Surprisingly, we detected the activation of angiogenic and survival pathways as compared to parental cells, which supports a multimodal approach to treat GBM CSC.

\section{RESULTS}

\section{Activation of PDGFR $\alpha /$ PDGF-AA signaling regulates expression of downstream genes Egr1, Stat 3 and Rb1 but not PKC $\alpha$ in GBM CSC}

Cancer stem cells from GBM were isolated as described previously $[23,24]$. We were able to collect either core- (c-CSC) or peritumor tissue-derived cancer stem cells (p-CSC) from several primary GBM samples; the two types of CSC had quite different tumorigenic potential and exclusive genetic anomalies [23, 24]. To demonstrate that the high expression of PDGFR $\alpha$ in p-CSC2 [23], confers a higher PDGF response than in c-CSC2, both cell types, were growth factors starved and then, exposed to exogenous PDGFAA $(50 \mathrm{ng} / \mathrm{ml})$ over a time course. In these experimental conditions (Figure 1A), we found more rapid activation of p-Erk1/2 in p-CSC2 than in c-CSC2 as reported previously [23]. Moreover, Egr1 (Early growth response 1) protein and Stat3 Y705 phosphorylation were induced as early as 5 minutes after PDGF-AA stimulation (Figure 1A). Strikingly, we noted a tight correlation between this phosphorylation event and the transient decrement of the tumor suppressor $\mathrm{Rb} 1$ in its active state, that occurred within 10 minutes, as detected by a monoclonal antibody that specifically recognizes hypophosphorylated active Rb1 (hypo-Rb1). A densitometric analysis (data not shown) showed a 70\% signal reduction at this time point compared to time point zero, followed by a gradual recovery. The engagement of PDGFR $\alpha$ with its ligand induced the gradual disappearance of the receptor 2 hours after PDGF-AA stimulus. The high expression and phosphorylation of $\mathrm{PKC} \alpha / \beta \mathrm{II}$ isoforms was not altered by PDGF-AA stimulation in either cell populations (Figure 1A).

\section{Block of PDGFR $\alpha$ activity by Crenolanib reduces the phosphorylation of Rb1 and Stat3 Y705}

To assess whether the decrement of hypo-Rb1 was PDGFR $\alpha /$ PDGF-AA axis-dependent, a time course 
experiment was performed to evaluate the effects of PDGF-AA applied alone or in combination with Crenolanib (CR, a potent inhibitor of PDGFR signaling), on p-CSC2 two days after growth factors withdrawal. Rb1 phosphorylation was monitored at short time intervals (510-30-120 minutes) up to 24 after the start of PDGF-AA stimulation. CR-treated cells showed upregulation of the hypo-Rb1 between 5 and 30 minute after the treatment as compared to PDGF-AA alone. A densitometric analysis (data not shown) showed an increase of 50\% of hypoRb1 signal within the first half hour in CR-treated cells compared to PDGF-AA alone. Two hours after the treatments the levels of the hypo-Rb1 return to baseline (Figure 1C). In contrast, Stat3 Y705 phosphorylation remained silenced at 24 hours by CR treatment (Figure 1B). Previous studies showed that the epidermal growth factor receptor (EGFR) could be transactivated by PDGFs stimulation and that EGFR transactivation was required for PDGF-stimulated cell migration [18]. In corroboration, we showed that PDGF-AA induced EGFR Y1068phosphorylation, and EGFR transactivation was inhibited by Crenolanib treatment (Figure 1B). CR was also found to upregulate Erk1/2 downstream of both the PDGFR and the EGFR (Figure 1B).

\section{shPDGFR $\alpha$-GBM CSC display changes in cell morphology and EMT phenotypes, which correlate with modifications in the molecular profile}

To demonstrate the central role of PDGFR $\alpha$ in CSC proliferation and differentiation, we interfered with PDGFR $\alpha$ gene expression using short hairpin RNA (shRNA) sequences transduced by a lentivirus-based system. We selected two PDGFR $\alpha$-directed shRNA clones (1 and 3) of p-CSC2 that displayed a robust silencing of
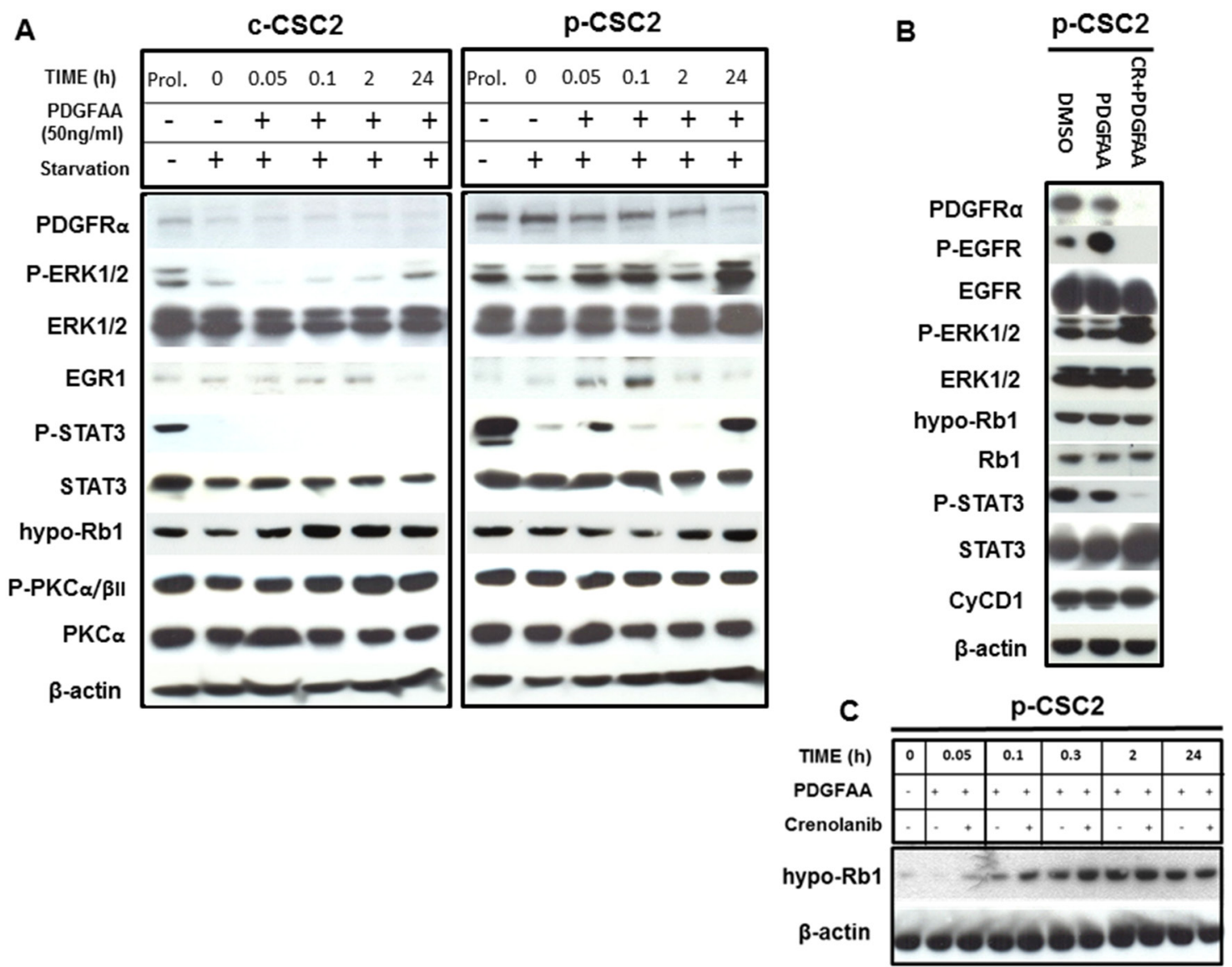

Figure 1: Activation of PDGFR $\alpha / P D G F-A A$ axis induces different modulation of target genes in GBM p-CSC2 than in c-CSC2. A. Time course experiment of the effects of PDGF-AA on immediate early genes activation in c-CSC2 vs p-CSC2 after 2 days of growth factors starvation. p-CSC2 express Egr1 and Y705-phosphorylated Stat3 after 5 minutes, on the other hand, hypo-Rb1 is significantly downmodulated in p-CSC2 after 10 minutes of treatment. Instead, the levels of T638/641-PKC $\alpha / \beta$ II remain stable at all time points. B. PDGF-AA applied alone or with CR for 24 hours on p-CSC2. Stat3 Y705 phosphorylation levels are impaired by CR treatment, instead hypo-Rb1 and total Rb1 protein expression are not affected after 24 hours by PDGFR inhibition. Cyclin D1 protein levels are not modulated in the same conditions. $\beta$-actin is used as control of equal proteins loading. $\mathbf{C}$. Time course experiment to evaluate the effects of PDGF-AA alone or combined with CR on the regulation of hypo-Rb1 in p-CSC2. CR upregulates hypo-Rb1 expression respect to PDGFAA alone. 
PDGFR $\alpha$ compared to transduced control cells ( $\mathrm{pLKO} .1$ ) (Figure 2A). Depletion of PDGFR $\alpha$ expression was associated with a reduction in cell growth as reported previously [23], and with a concomitant impairment of neurosphere formation ability, consistently observed over the entire seven days of time course (Figure 3). The two cell clones showed evident morphological changes if induced to differentiate in presence of 5\% FCS. After 2 and 4 days in differentiation conditions, shPDGFR $\alpha-C S C$ showed an epithelial cell morphology, with formation of adherent cell clusters and few cells with an elongated phenotype. In contrast, the pLKO.1 control cells showed a flat morphology with a clear mesenchymal phenotype, evenly distributed on the plate (Figure 4). These observations prompted us to explore the gene expression

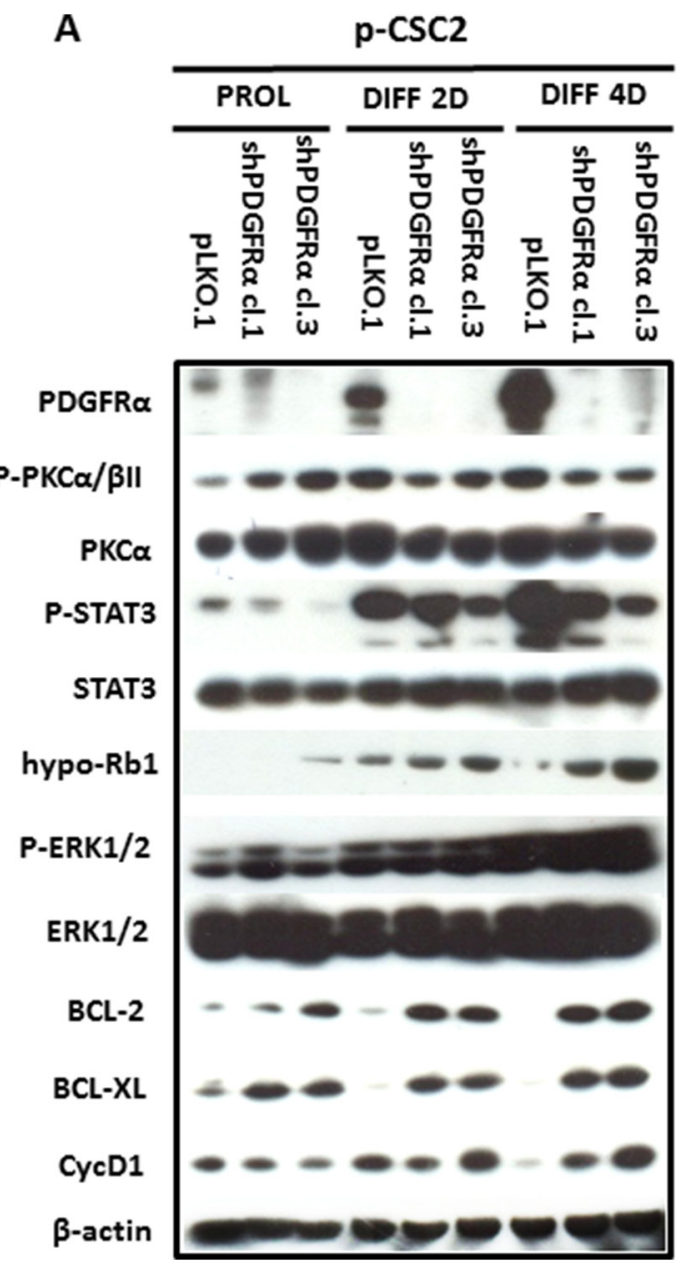

of epithelial cell junction proteins such as E-cadherin (CDH1) and VE-Cadherin (CDH5) or ECM molecules such as fibronectin (FN1) by a RT-qPCR analysis. CDH1 mRNA expression was monitored in PDGFR $\alpha$-depleted CSCs during cell proliferation. Both clone 1 and 3 showed higher expression compared with control cells, with a fold change of 13.1 and 13.6 respectively in proliferating cells and with a peak of activation at 15.2 and $17.3 \mathrm{Fc}$ after 4 days of differentiation (Figure 5). Our finding were consistent with that published in various cell lines, reporting an inverse correlation between $\mathrm{CDH} 1$ expression and invasiveness [25]. CDH5 mRNA levels were drastically downmodulated in proliferating cell clones and reached 0.35 and $0.36 \mathrm{Fc}$ in 4 days-differentiated cells respectively (Figure 5). Similarly, FN1 mRNA expression

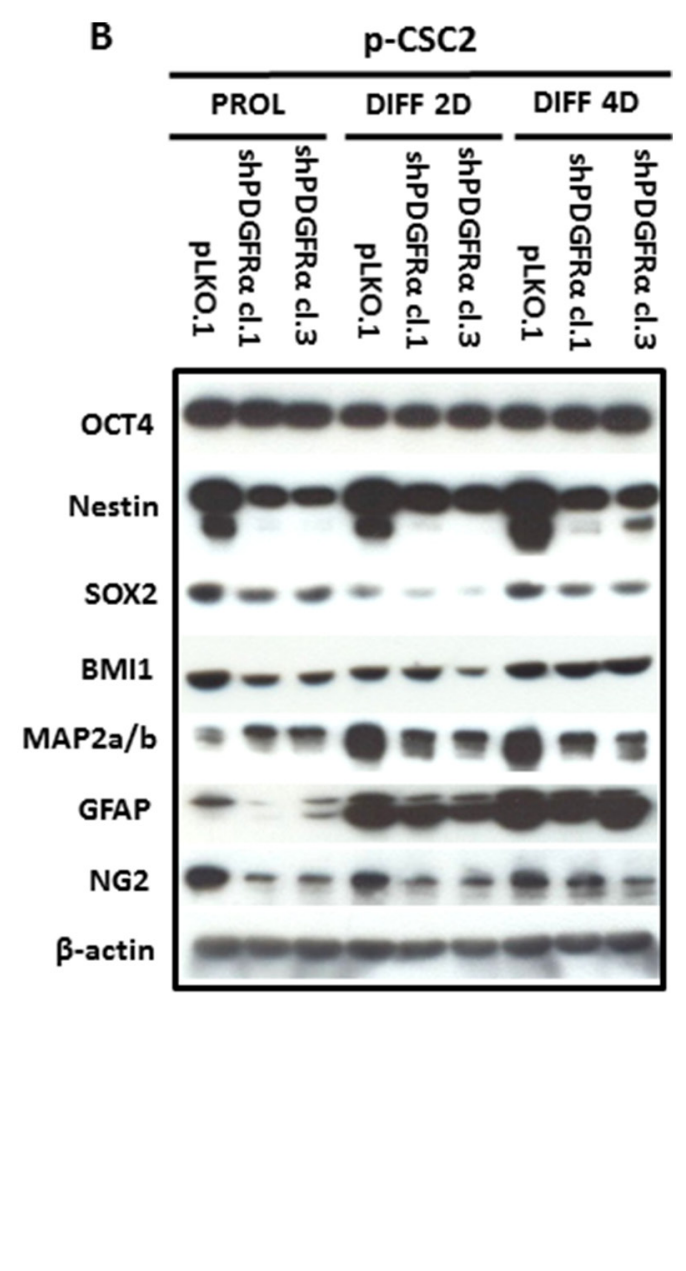

Figure 2: Modulation of multipotency, differentiation and survival markers in PDGFR $\alpha$-depleted GBM CSC vs control cells. A. Western blot analysis reveals that depletion of PDGFR $\alpha$ in p-CSC2 induces the downmodulation of Stat 3 Y705 phosphorylation in both proliferating cell clones, instead their levels raised up in differentiation conditions. The hypo-Rb1 levels result overexpressed in clone 3 in all conditions. Instead the clone 1, shows an increase of hypo-Rb1 at 2 and 4 day of differentiation with respect to pLKO.1 cells. In parallel, Bcl-2 and Bcl-xL proteins and Erk1/2 pathway were upregulated in both cell clones in comparison with pLKO.1 cells in differentiaton conditions. T638/641 phosphorylated-PKC $\alpha / \beta I I$ isoforms expression levels are slightly induced in proliferating PDGFR $\alpha-$ depleted cell clones, but negatively modulated in differentiated ones than pLKO.1 cells. B. The downmodulation of multipotent protein markers (Nestin, Sox2, Bmi1), except for Oct4, is accompanied with early induction of the neuronal marker MAP2a/b in proliferating PDGFR $\alpha$-depleted cell clones vs pLKO.1. Similar results were observed during cell differentiation, except for MAP2a/b that increases in pLKO.1 with respect to PDGFR $\alpha$-depleted cells. 
was diminished to 0.34 and 0.38 fold in proliferating shPDGFR $\alpha$-CSC clones compared to pLKO.1, and went down to 0.16 and $0.15 \mathrm{Fc}$ in 2 days-differentiated cells. Similar results were seen at 4 days (Figure 5). As reported by the literature, the combined loss of $\mathrm{CDH} 1$, and the gain of mesenchymal markers, such as vimentin, FN1 and $\mathrm{N}$-cadherin favor the EMT program [26].

\section{PDGFR $\alpha$ depletion downmodulates stemness- related and glial markers, induces early expression of neuronal marker and RB1 but does not affect PKC $\alpha$ in GBM p-CSC}

To assess the role of PDGFR $\alpha$ in the regulation of stemness of GBM CSC, we carried out Western blots and RT-qPCR to elucidate the effects of a diminished PDGFR $\alpha$ expression on stemness-related genes. We observed a decrease in protein expression for Nestin, Sox2, Bmi1, but no modulation of Oct4 (Figure 2B). RT-qPCR analysis confirmed the decrease of SOX2 mRNA to 0.11 and 0.13 fold in clone 1 and 3 compared to control cells. Similar results were confirmed at 2 and 4 days-differentiated p-CSC2 (Figure 5). Attenuation of stemness in shPDGFR $\alpha$-CSC clones correlated with early induction of late neuronal differentiation marker MAP $2 \mathrm{a} / \mathrm{b}$ protein in proliferating cells (Figure 2B), also monitored as mRNA (data not shown). Genetic and pharmacological depletion of PDGFR $\alpha$ triggered the activation of tumor suppressor RB1 gene, a key factor controlling cell cycle exit and differentiation in several cell models. As shown in Figure 5, PDGFR $\alpha$-depleted CSC clone 1 and 3 displayed the induction of RB1 mRNA up to 2.35 and 2.59 fold respectively compared to control cells. Expression levels raised a peak to 3.59 and $3.45 \mathrm{Fc}$ in 4 days-differentiated

\section{DAYS}

\section{DAYS}

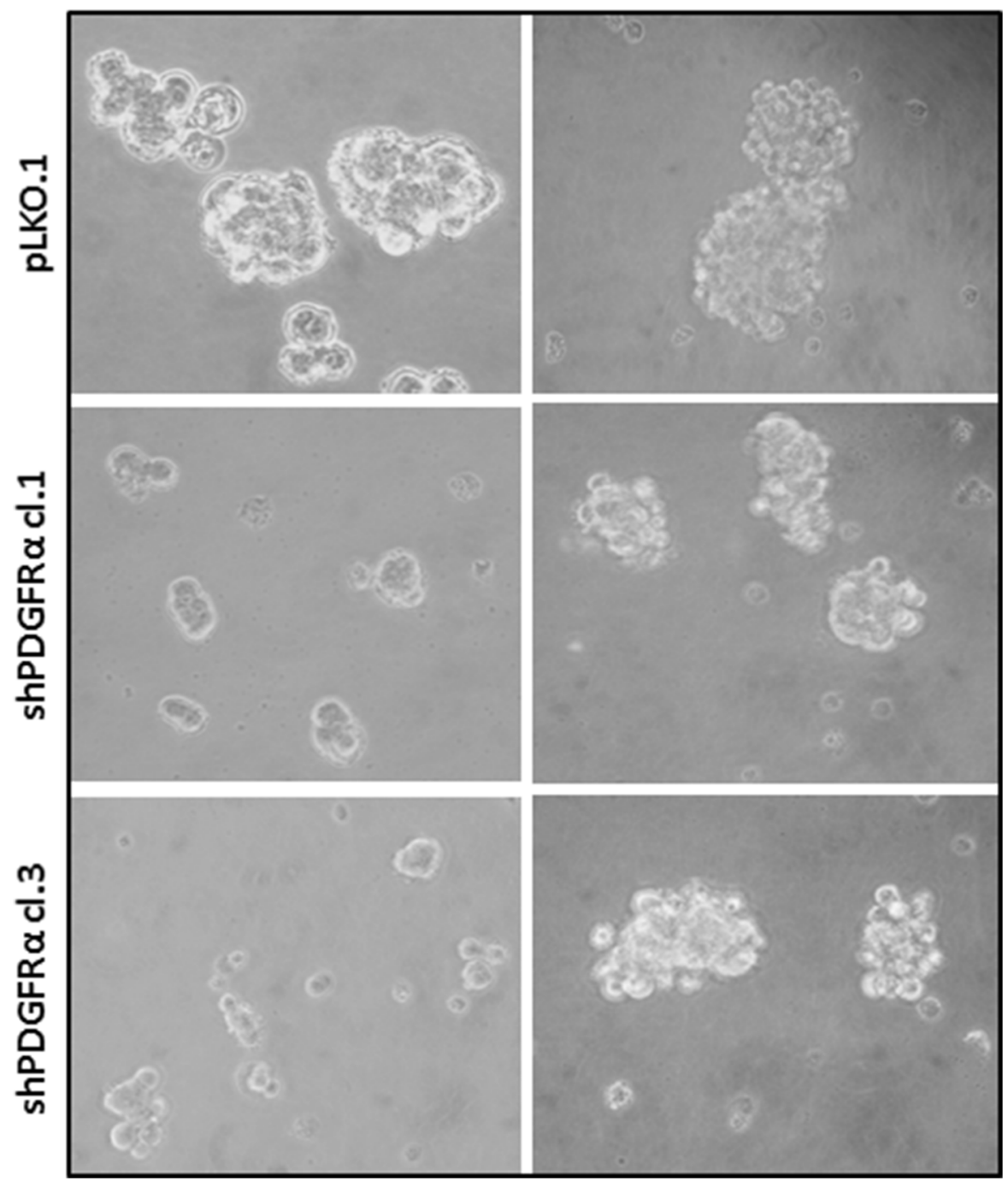

Figure 3: Neurospheres formation impairment of PDGFR $\alpha$-depleted GBM CSC vs control cells. Microscopic analysis at 3 and 7 days in growth conditions reveals a diminished ability of p-CSC2 depleted of PDGFR $\alpha$ to make neurospheres in vitro compared to control cells (pLKO.1) over the entire course of the experiment. 
cells respectively. Western blot analysis revealed the increase of hypo-Rb1 in proliferating clone 3 , or in both differentiated clones compared to pLKO.1 (Figure 2A). Under the same culture conditions, we noticed a decrease of Stat3 Y705-phosphorylation in both clones in comparison to pLKO.1 cells (Figure 2A). Conversely, we reported a diminished expression of glial fibrillary acidic protein (GFAP) and the chondroitin sulfate proteoglycan NG2 (Figure 2B). The latter is probably the result of lack of a physical association with PDGFR $\alpha$, which is an obstacle to the formation of new oligodendroglial precursors NG2+ve [28]. The reduced PDGFR $\alpha$ expression correlated with higher levels of Bcl-2 and Bcl-xL compared to control cells, suggesting a potential role of these genes in cell survival in either proliferating or differentiated cells. These results paralleled with an increase in $\mathrm{CycD} 1$ protein in differentiated cells and a slight decrease in proliferating cells. The latter effect likely correlated to cell proliferation impairment induced by PDGFR $\alpha$ deletion. Because of the critical role of PKC $\alpha$ in promoting EMT phenotype and malignant progression of glioblastoma cells, we hypothesized that $\mathrm{PKC} \alpha$ could regulate stemness of GBM CSC downstream of the PDGFR $\alpha$ signaling cascade. To answer the question, we performed shRNA targeting of $\mathrm{PKC} \alpha$ expression in GBM p-CSC2. The results revealed no variation of the multipotent stem cells markers Nestin or Sox2, even with the addition of PDGF-AA for three days (Figure S1). This finding reveals that $\mathrm{PKC} \alpha$ is probably not involved in regulation of stemness through the PDGFR $\alpha$ signaling.

\section{PDGFR $\alpha$ depletion inhibits the invasiveness of GBM CSC and triggers EDN1 signaling, PDGF-C and PDGF-D expression}

Formerly we reported that GBM p-CSC2 displayed higher invasive capacity through Matrigel with respect to the counterpart c-CSC2 [23]. Herein, we aim to demonstrate

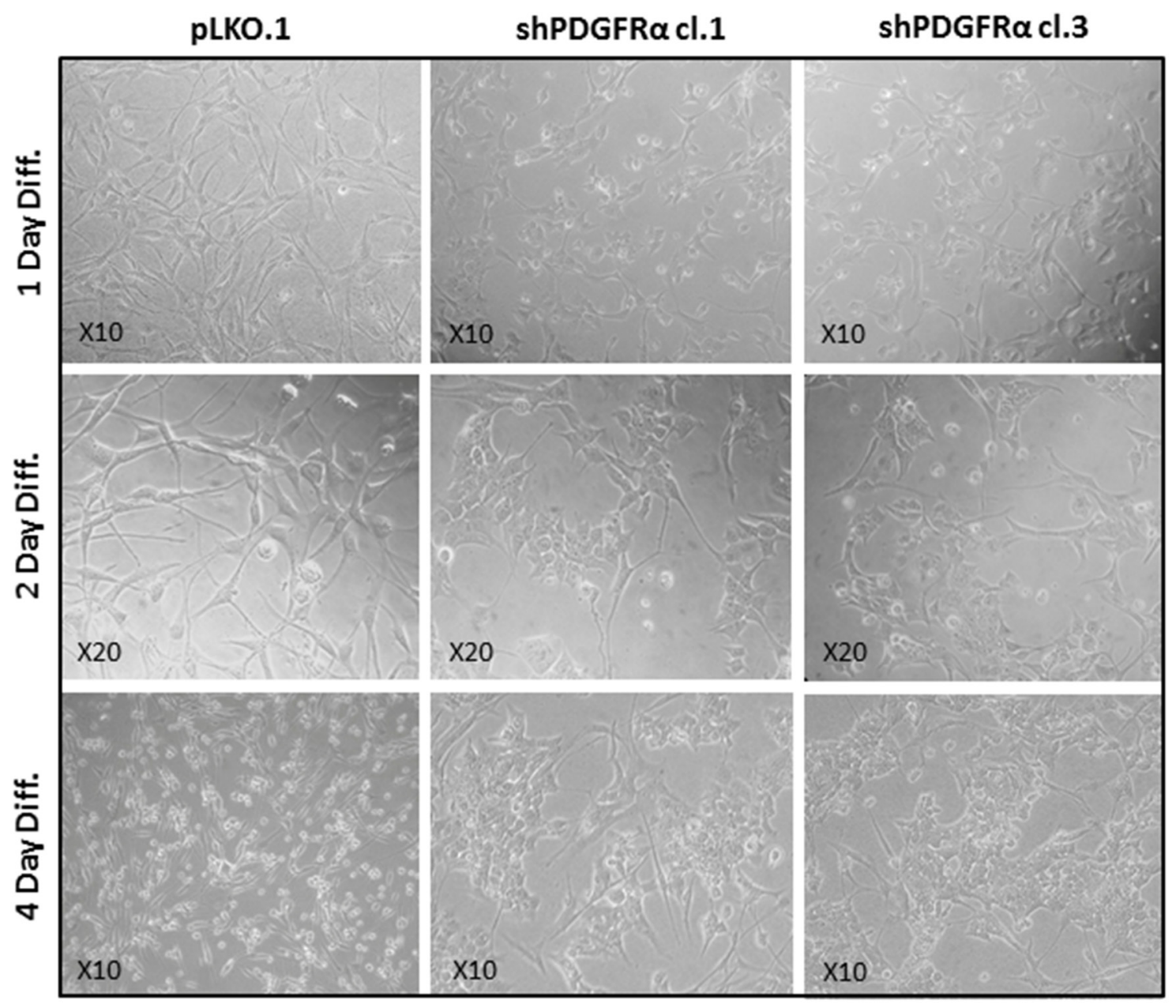

Figure 4: PDGFRa-depleted GBM CSC show phenotypic changes vs control cells. Phase-contrast images captured after 1-2-4 days in differentiation conditions revealed morphological changes between shPDGFR $\alpha$-CSC clone 1 and clone 3 in comparison with pLKO.1. The aspect of pLKO.1 cells is more similar to the mesenchymal phenotype with a flat cell morphology. Conversely, the shPDGFRCSC cell clones displayed an epithelial appearance with crowded cell clusters among few elongated cells, which is clear manifested at 4 days of the cell differentiation. 
the role of PDGFR $\alpha / \mathrm{PDGF}-\mathrm{AA}$ axis in the regulation of the invasive capacity of p-CSC2. Using an in vitro cell invasion assay we demonstrated a significant reduction in PDGF-AA stimulated invasion of shPDGFR $\alpha$-CSC clones compared to pLKO.1. Demonstrating specificity, no difference in the invasive capacity was observed using EGF as chemoattractant (Figure 6A). The EMT leads to a reduced cellular adhesion, changes in cytoskeletal organization and acquired potential for cell migration, all this process is associated to changes in expression of transcription factors [30]. To corroborate the role of PDGFR $\alpha$ on the invasive phenotype of p-CSC2, we completed the RT-qPCR analysis of critical genes for EMT such as ZEB1, ZEB2, TWIST1 and Vimentin (VIM). Our results displayed a significant
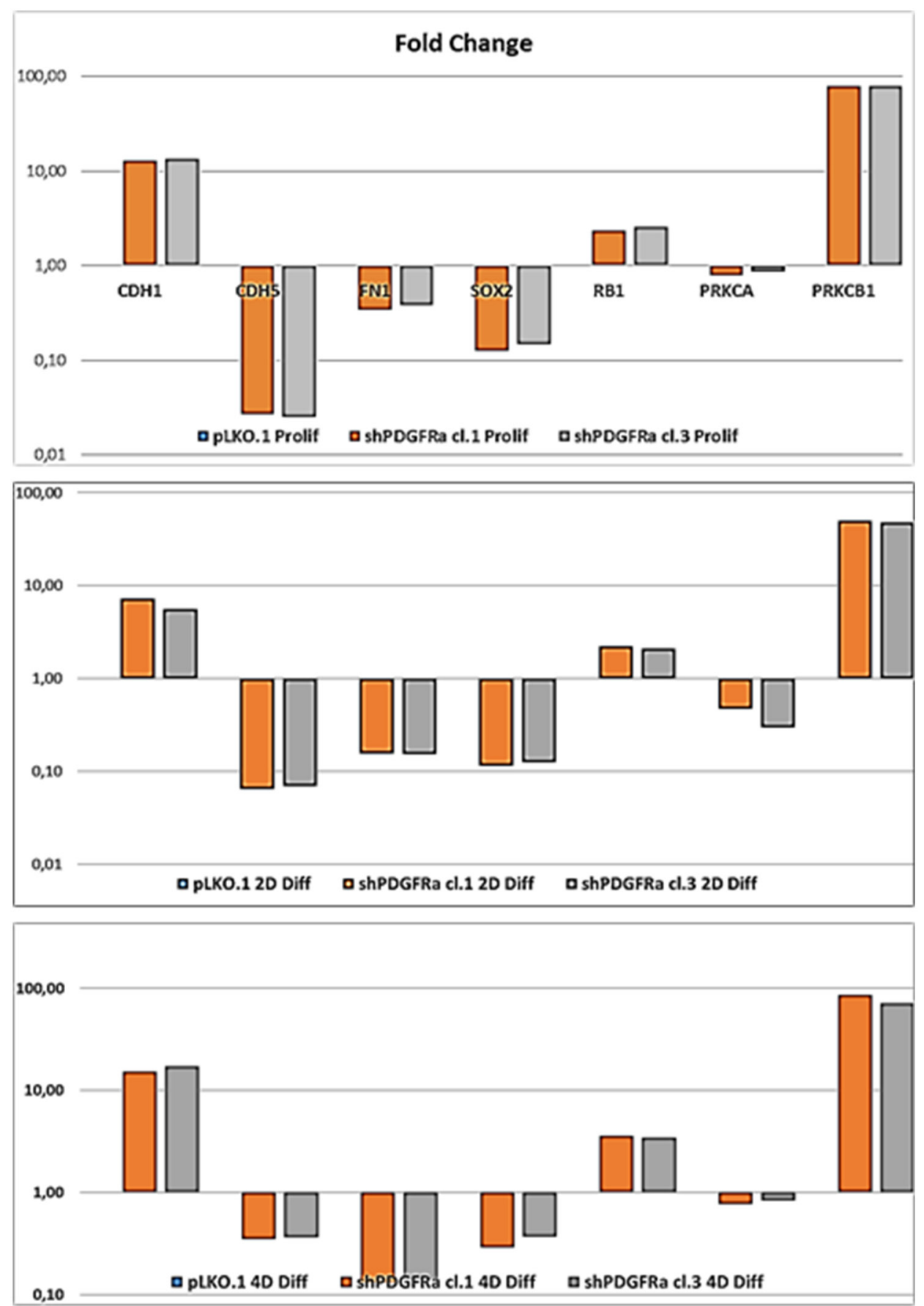

Figure 5: PDGFR $\alpha$ deletion induces different expression of target genes in GBM CSC in proliferation and differentiation conditions. RT-qPCR analysis shows a significant modulation of gene expression of cell-cell (CDH1, CDH5) and cell-substrate (FN1) molecules interactions, the stem cell marker SOX2 and oncogenic signaling molecules (PRKCA, PRKCB1). Progressive upregulation of the tumor suppressor RB1 and PRKCB1 isoform during cell differentiation is shown. Results represent the mean of two independent experiments performed in triplicate. Fold change $(\mathrm{Fc})$. 
decrease of VIM, ZEB1, ZEB2, but not TWIST1 in both proliferating cell clones (Figure 6B). Similarly, we noticed a decrease of angiogenic markers (Figure 6B) such as VEGFR2, PECAM1 (CD31), and CDH5 as shown previously (Figure 5). In parallel, Western blot analysis display a significant decrease of CD31, VEGFR2 and VECadherin proteins, corroborating mRNA expression levels (Figure 6C). Unexpectedly, we noticed an increase of mRNA expression for endothelin1 (EDN1), the receptor EDNRB (Figure 6B), its target gene PRKCB1, but not PRKCA (Figure 5). In Figure 5 we reported a significant upregulation of PRKCB1 gene expression in proliferating (79.4 and 78.9 Fc respectively) and differentiated PDGFR $\alpha$ depleted cell clones 1 and 3 (86.3 and 71.8 Fc respectively) compared with pLKO.1. Instead, PRKCA gene expression was slightly reduced either in proliferating $(0.78$ and 0.86 Fc respectively) or differentiated PDGFR $\alpha$-depleted cell clone 1 and 3 (0.7 and $0.8 \mathrm{Fc}$ respectively). Consistently,
PKC $\alpha$ protein expression and phosphorylation of PKC $\alpha$ / $\beta$ II isoforms are reduced in differentiation conditions in cell clones compared to pLKO.1 (Figure 2A). In as much as peritumor tissue-derived CSC presented greater chemoresistance to treatments respect to core tumor derived-CSC [23], we decided to investigate by RT-qPCR the expression of the main modulators of EMT and/or drug resistance such as TWIST, EDN1 and PRKCA in several samples of GBM CSC (Figure 7B). We observed a slight increase of PRKCA in p-CSC compared to respective c-CSC pools, except for CSC5. EDN1 and TWIST expression levels were upregulated several fold in the majority of $\mathrm{p}-\mathrm{CSC}$ in comparison to c-CSC (Figure 7A). We examined the mRNA expression profile of PDGF ligand isoforms in PDGFR $\alpha$ depleted cells. Interestingly, we noticed that PDGF-C and PDGF-D were highly expressed in proliferating PDGFR $\alpha$ depleted CSC as compared to pLKO.1 cells. PDGF-C reached 2.8 and $3.2 \mathrm{Fc}$ in proliferating clonel and 3
A

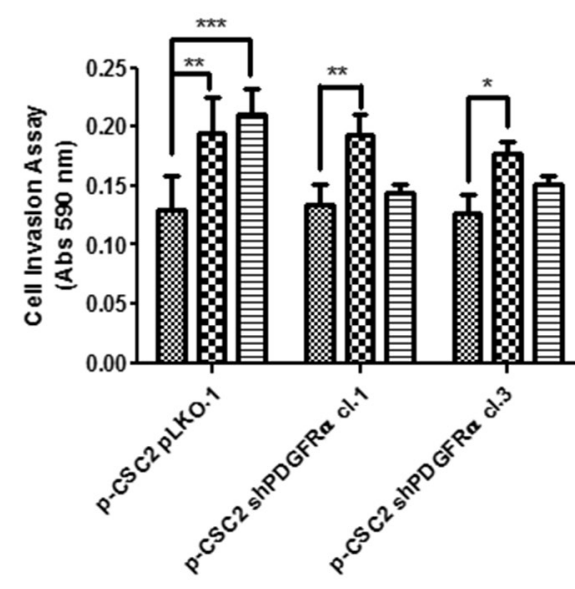

B

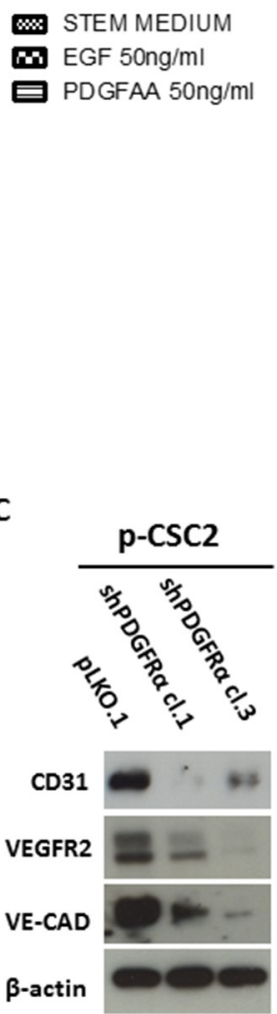

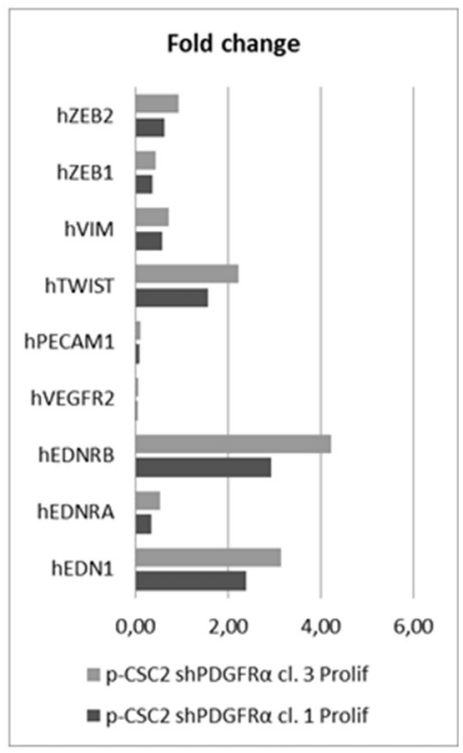

Figure 6: shPDGFR $\alpha$-CSC clones display a significant reduction of invasiveness and angiogenesis compared to pLKO.1. A. In the absence of growth factors (Stem Medium) all cells display the same invasive capacity. Addition of EGF promoted invasiveness in both cell clone 1 and $3 v s$ pLKO.1 cells. PDGF-AA addition significantly promoted pLKO.1 cells invasion but does not affect p-CSC2 shPDGFR $\alpha$ cell clones invasiveness. B. RT-qPCR analysis of key genes for angiogenesis and EMT. PECAM1, VEGFR2 are dramatically repressed in p-CSC2 shPDGFR $\alpha$ clone 1 and 3 with respect to pLKO.1. EDN1 and its receptor EDNRB are upregulated in PDGFR $\alpha$-depleted cells compared to pLKO.1. The main EMT markers such as ZEB1, ZEB2 and VIM, except for TWIST, are significantly downmodulated in PDGFR $\alpha$-depleted cells compared to pLKO.1 cells. Error bars represent the mean \pm SD of two independent experiments performed in triplicate. *, $\mathrm{P}<0.05, * *, \mathrm{P}<0.01 * *, * * *, \mathrm{P}<0.001$ vs. control. C. Western blot analysis for endothelial markers in $\mathrm{p}$-CSC2 shPDGFR $\alpha$ clone 1 and 3 with regard to pLKO.1. A significant decrease is reported for CD31, VEGFR2 and VE-cadherin proteins in PDGFR $\alpha$-depleted cell vs control cells. 
respectively, while PDGF-D reached a peak of 8.3 and 8.9 Fc respectively. At 2 and 4 days-differentiated cells these values were significantly higher: PDGF-C reached a peak at day 4 with 8.5 and $8.7 \mathrm{Fc}$ in clone 1 and 3 respectively, instead PDGF-D raised up to 13.8 and $16.8 \mathrm{Fc}$ respectively as compared with pLKO.1 (Figure 7B).

\section{DISCUSSION}

Our work aimed to assess the role of PDGFR $\alpha$ signaling in self-renewal, differentiation, invasion and EMT phenotype in glioblastoma CSC through the knockdown of PDGFR $\alpha$ expression. Previous studies showed that either genetic or pharmacological targeting

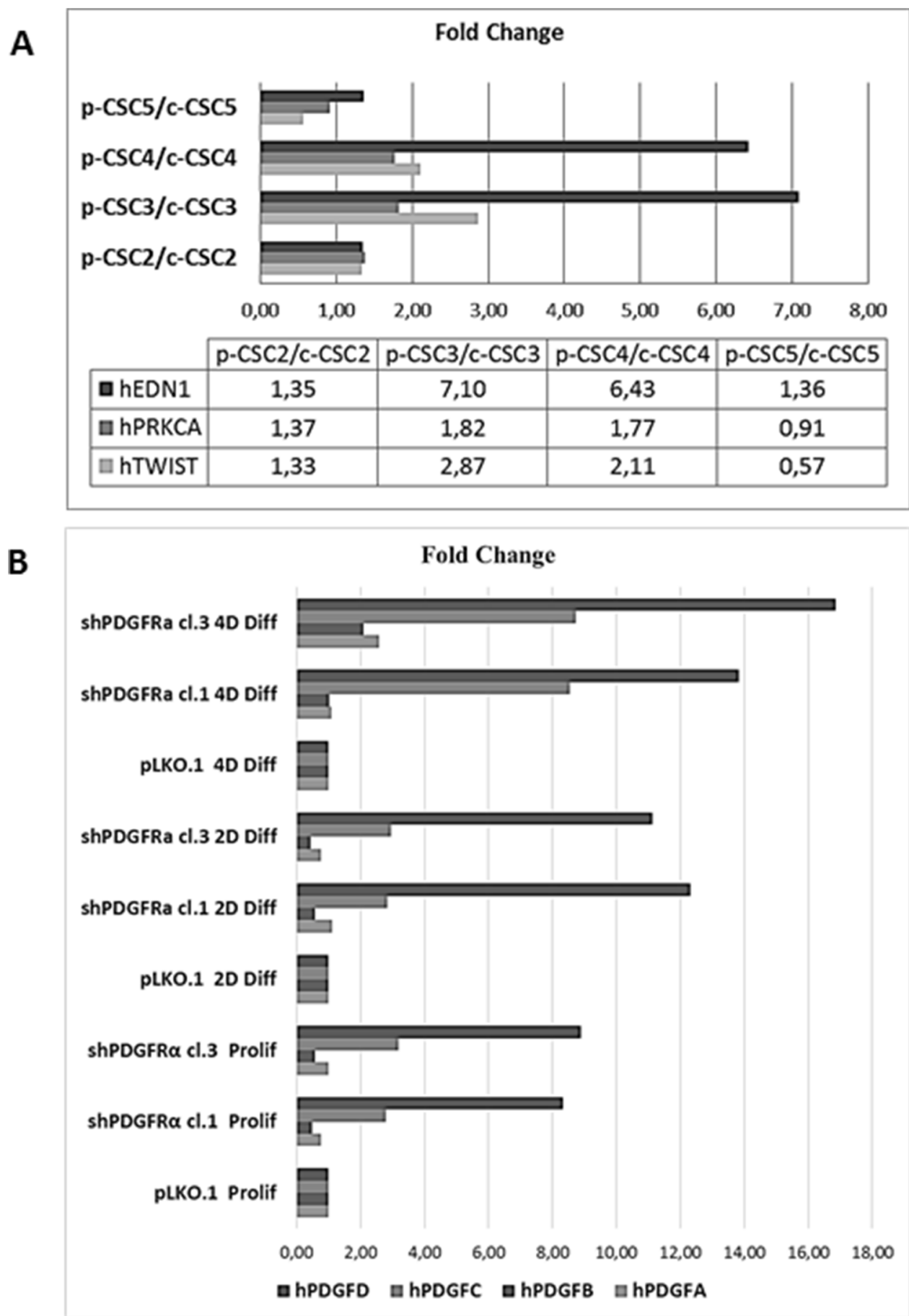

Figure 7: RT-qPCR analysis of EMT markers in several GBM CSCs and of PDGF isoforms profile in pCSC2 shPDGFRa vs pLKO.1. A. We compared several GBM p-CSCs vs the respective GBM c-CSCs for EDN1, PRKCA and TWIST mRNA expression. B. mRNA expression profile of PDGF isoforms highlights the elevated induction of PDGF-C and PDGF-D in p-CSC2 shPDGFR $\alpha$ vs pLKO.1 either in proliferating or differentiated cells. Results represent the mean of two independent experiments performed in triplicate. 
of PDGFR $\beta$ or PDGFR $\alpha$ inhibited self-renewal, survival, tumor growth and invasiveness of GBM CSC [7, 23]. Overexpression of PDGFR $\alpha$ in p-CSC of six GBM cases published previously by our group prompted us to make the hypothesis that peritumor tissue-derived GBM CSC might be more responsive to inhibition of PDGFR activity [23]. In fact, we have shown that a highly potent inhibitor of PDGFR activity, Crenolanib, induced apoptosis in several GBM CSC (p-CSC and c-CSC) which increased in combination with the inhibition of EGFR activity [23].

In order to understand the meaning of PDGFR $\alpha$ overexpression in GBM p-CSC2, we tested the effects of PDGF-AA stimulation on expression of canonical target pathways such as Erk1/2, Stat3, Egr1. Transient Stat 3 activation occurred at early time points and, it was subsequently turned off. At later time points, Stat3 activation was once more increased. This latter effect is most likely indirect and it is mediated by progrowth signals triggered by PDGFR $\alpha / P D G F-A A$ positive loop. In the same experiment, we observed a transient downmodulation of hypo-Rb1, which represents inactivation of the tumor suppressive function of Rb1 downstream of the PDGFR $\alpha /$ PDGFAA axis. The subsequent recovery of hypo-Rb1 expression correlated with a decrease in PDGFR $\alpha$ expression. The block of PDGFR $\alpha$ activity by Crenolanib also increased the hypo-Rb1 levels with respect to PDGF-AA alone, and returned to steady state levels at later time points. This observation suggests that Rb1 and PDGFR signaling are interconnected to control cell fate, but more experiments are warranted to elucidate the molecular mechanisms of this relationship.

The induction of the transcription factor Egr1, a member of a zinc-finger transcription factor family, goes in the direction of an oncogenic regulatory loop directed by PDGF-AA. Accordingly Sakakini et al. reported that the nuclear expression of Egr1 is restricted to proliferating cells in high-grade gliomas, and in primary cultures of glioma stem-like cells, Egr1 contributes to stemness marker expression and proliferation by orchestrating a PDGF-AA-dependent growth stimulatory loop [28].

A prominent effect induced by PDGFR $\alpha$ depletion in GBM CSC was cell growth impairment and an associated reduction in ability of GBM CSC to make neurospheres in vitro. PDGFR $\alpha$ deletion also contributed to a reduced expression of stemness-associated genes as well as the downmodulation of EMT and angiogenic markers. A schematic representation of biological and molecular effects triggered by silencing of PDGFR $\alpha$ in GBM CSC is shown (Figure 8). EMT is a physiological process occuring during embryogenesis that appears to be reinstated under certain pathological conditions, such as cancer. In the EMT process, epithelial cells lose apico-basal polarity and

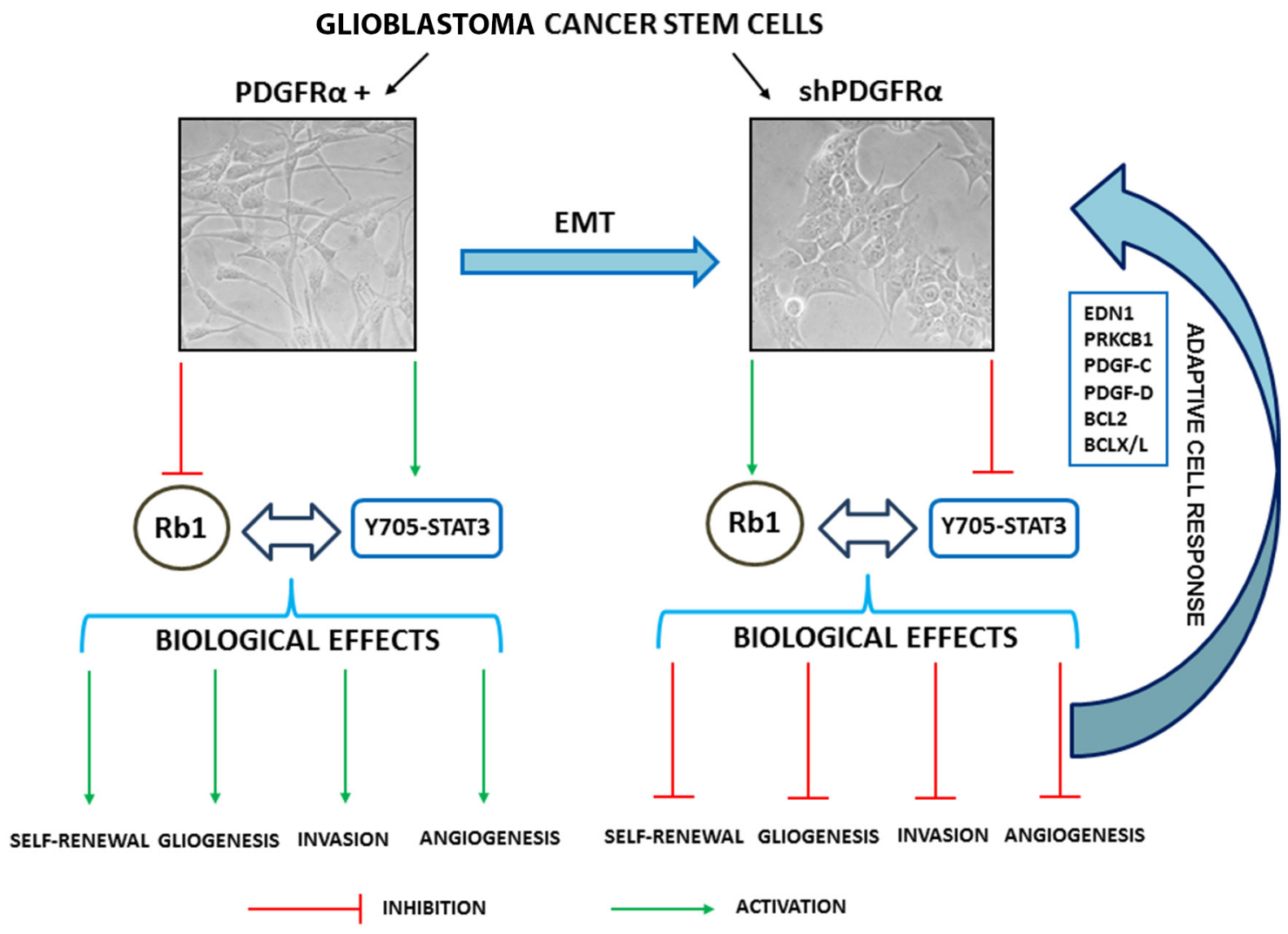

Figure 8: Schematic representation of the biological and molecular effects triggered by depletion of PDGFR $\alpha$ in GBM p-CSC2. 
gain properties of mesenchymal cells, and become motile and invasive [29-31].

PDGFR $\alpha$-depleted CSC revealed the concomitant upregulation of angiogenic and survival pathways apparently in contrast with the downmodulation of endothelial markers such as VEGFR2, PECAM1 and VECadherin. We hypothesize that GBM CSC counteracted angiogenic inhibitory signals by activation of progrowth and prosurvival signals, which comprise PDGF-C, PDGF-D, EDNRB/EDN1/PRKCB1, Bcl-2/Bcl-xL and extracellular signal-regulated kinase (Erk1/2) signaling pathways [8, 32-36]. Several studies have demonstrated that PDGF-C and PDGF-D expression were ubiquitous in brain tumor cells and tissues but were very low or absent in normal adult and fetal brain [35]. High levels of those soluble factors in glioma specimens are associated with more rapid disease recurrence and poorer overall survival [35]. PDGF-C has been reported to induce angiogenic activity indirectly, via upregulation of VEGF and directly, via activation of PDGFR $\alpha$. In particular, PDGF-C plays an important role in glioma vessel maturation and permeability, and can attenuate the response and escape from anti-VEGF therapy [35]. In vitro studies reported that inhibition of Bcl-2/Bcl-xL, along with an antitumor agent that induces TRAIL pathway-mediated cell death give a strong synergistic anti-proliferative effect on pediatric, adult, proneural GBM and glioma stem-like cells [36]. Our data support the existence of autocrine and paracrine signals and implicate for a role of PDGF-C, -D and EDN1 signaling in GBM tumor growth. Liu and colleagues reported that EDN3/EDNRB signaling is involved in maintaining GBM CSC migration, stemness and survival [33].

Dong et al. reported that the selective inhibition of PDGFR by the Imatinib, a drug analog of Crenolanib, elicited the activation of Erk1/2 in malignant glioma cells. The activation of Erk1/2 induced by the Imatinib treatment was related to the S-phase re-entry of the cell cycle in one of the three glioma cells tested [38]. Evenly the up regulation of CycD1 observed in PDGFR $\alpha$-depleted cells compared to pLKO.1, particularly evident at 4th day of differentiation, would agree with the presence of autocrine and paracrine mitogenic stimuli as argued previously. The overall results reinforce the rationale of using combined anti-angiogenic and multiple approaches to improve the therapeutic response for GBM $[39,35,9]$.

Tam and colleagues reported that $\mathrm{PKC} \alpha$ overexpression upregulates AP1, which in turn mediates Notch4 activity [40]. Activated Notch4 is closely associated with the promotion of estrogen-independence and chemotherapy resistance in breast cancer cells. In different cell contexts such as intestinal, pancreatic and mammary cells, PKC $\alpha$ has anti-proliferative effects [41]. $\mathrm{PKC} \alpha$ is a downstream target of PDGFR signaling and despite the constitutive phosphorylation on T638-641, it does not appear to be modulated at transcriptional level in proliferation and differentiation conditions. Nevertheless, we hypothesized that $\mathrm{PKC} \alpha$ could be involved in stemness regulation in GBM CSC, but unexpectedly we noticed no significant modulation of the multipotency stem cell markers Nestin and Sox2 in PKC $\alpha$-depleted CSC as compared to parental cells. Further experiments needed to clarify the role of PKC $\alpha$ in the maintenance, invasiveness and differentiation of GBM CSC. Our data led us to assume a compensatory mechanism as described formerly because of the increase of PRKCB1 gene expression, however this result is not consistent with the levels of T638-641 phosphorylation of PKC $\beta I I$ isoform and we think that the issue should be addressed in details. For PKC $\beta$ isoforms there are conflicting reports, as some indicate PKC $\beta$ expression, while others not [42]. Clinical studies have evaluated the acceptable tolerability of enzastaurin (an inhibitor of PKC $\beta$ and PI3K/AKT) in patients with recurrent GBM, but the authors reported that it did not have a superior efficacy of the alkylating agent Lomustine [43, 44]. However, there is a paucity of data on the role of PKC $\beta$ isoforms in CSC and further experiments are required to reveal their role in glioma pathogenesis.

We have reported the up regulation of $\mathrm{RB} 1$ at transcriptional and protein level in its active state in PDGFR $\alpha$-depleted CSC either in proliferating or differentiated CSC, which correlated with Stat3 activity decline. Our data reported for the first time that the PDGFR $\alpha /$ PDGF-AA axis is a regulator of the crosstalk between Stat 3 and $\mathrm{Rb} 1$ signals. In the current study, Stat 3 seems to play a dual role as oncogene and tumor suppressor in GBM CSC. Evidences from the literature, report Stat 3 persistently phosphorylated and associated with an unfavorable prognosis in GBM. In the current study, the markers of neural stem cell multipotency decrease as much as Stat3 activity decreased upon PDGFR $\alpha$ inhibition, suggesting that Stat 3 is required for maintenance of the stem-like features of these cells $[1,13]$. Furthermore, JAK-Stat signaling pathway selectively enhanced differentiation of neural stem cells towards a glial lineage and inhibited differentiation of neural precursors along a neuronal lineage $[11,12]$. Here we show that the upregulation of Stat 3 activity during GBM CSC differentiation is consistent with higher levels of GFAP with respect to PDGFR $\alpha$-depleted cells, which instead revealed a decrease of GFAP and NG2 expression and the early activation of neuronal marker MAP2a/b in proliferating cells [27]. Besides a role of PDGFR $\alpha$ in glial differentiation, the block of PDGFR $\alpha$ activity in vitro promoted the reduction of NG2 expression and tumor cells growth as reported by Pilkington [45]. Accordingly Chekenya et al. described that the grafting of NG2+ve GBM cell lines displayed an in vivo growth advantage, which was associated with tumor angiogenesis [46]. 
The Rb1 pathway is altered in almost $70 \%$ of human cancer types and this pathway is mutated in $78 \%$ of cases of GBM. Ichimura et al. reported that among $120 \mathrm{GBM}, 40 \%$ had no wild-type CDKN2A gene, 12\% amplified the CDK4 gene, and $14 \%$ had no wild-type RB1 gene [47], and the majority of the GMB (64\%) had only one of these abnormalities [48]. Nakamura et al. reported that $93 \%$ of tumors with $\mathrm{Rb} 1$ expression had a normal RB1 gene status [49]. In our paper, we reported higher expression of RB1 gene transcription and hypophosphorylated Rb1 protein in PDGFR $\alpha$-depleted GBM CSC compared to control cells, thus on the basis of the literature, we could assume that RB1 gene most likely has a normal status. On the other hand, we could not rule out CDKN2A and CDK4 gene alterations. In addition, the complexity of $\mathrm{Rb} 1$ pathway is often accompanied by gain-of-function of p53, resulting in dysregulation of tightly regulated cellular processes such as cell cycle, upregulation of survival and oncogenic signals as observed in our PDGFR $\alpha$-depleted GBM CSC [50]. Several preclinical and clinical studies aimed to inhibit the CDK4/CDK6 kinase activity as components that lead to Rb1 inactivation by hyperphosphorylation, and consequent suppression of cell cycle arrest [51-53]. We assumed that the $\mathrm{Rb} 1$ gene activation detected in PDGFR $\alpha$-depleted GBM CSC clones would promote anti-proliferative and anti-apoptotic effects and along with Stat3 might induce the molecular profile change observed in differentiated PDGFR $\alpha$-depleted GBM $\mathrm{CSC}$. $\mathrm{Rb} 1$ is also involved in other cellular processes such as the induction of terminal cellular differentiation, maintenance of genetic stability, protection from apoptotic insults in GBM and cancer stem cells [19, 48, 50-53].

After all we found that the inhibition of a single molecular target by a genetic approach or the application of receptor tyrosine kinase inhibitor as a single drug could provoke adaptive effects in tumor cells such as the activation of compensatory oncogenic signals [38]. Therefore, combination therapies could be a better way to kill tumor stem cells. As an example, Ziegler et al., demonstrated that the inhibition of PDGFR in human glioblastoma cells, is counteracted by inhibitor of apoptosis proteins (IAP), and concomitant inhibition of PDGFR with inactivation of IAPs resulted in increased apoptosis [38, 49].

Further experiments should be addressed to unveil the molecular mechanisms underlying the molecular crosstalk between $\mathrm{Rb} 1$ and Stat 3 pathways directed by PDGFR $\alpha /$ PDGFAA axis in GBM CSC. In fact, clinical trials are ongoing to target PDGFR amplification or Stat3 activity in patients with malignant gliomas. Unfortunately, the results of these clinical trials are not yet available, so it is early to draw conclusions. We hypothesize that the newly discovered $\mathrm{PDGFR} \alpha / \mathrm{Stat} 3 / \mathrm{Rb} 1$ regulatory axis might represent an appealing therapeutic target for GBM treatment.

\section{MATERIALS AND METHODS}

\section{Ethical statement}

Procedures for collection of adult human GBM CSC were approved by the Ethical Committee of the Catholic University of Rome as reported previously [24, 25]. The informed consent was obtained and all patients were fully aware of the aims and scope of this work. The ethical principles of the declaration of Helsinki, were strictly followed $[24,25]$.

\section{Cell culture of human glioblastoma cancer stem cells}

We have used the same clinical materials reported in our previous papers [24]. In brief, the CSC cells were retrieved from adult patients affected by GBM and undergoing craniotomy at the Institute of Neurosurgery, Catholic University-School of Medicine of Rome, Italy. Dissociated cells were cultured in proliferation medium containing human recombinant EGF $(20 \mathrm{ng} / \mathrm{ml}$; PeproTech, Rocky Hill, NJ), human recombinant bFGF (10 ng/ml; PeproTech), in DMEM/F12 (1:1) serumfree medium (Invitrogen, Carlsband, CA) as reported previously [24]. Floating neurospheres were dissociated with Accutase at $37^{\circ} \mathrm{C}$ (Merck-Millipore). Neurospheres culture were passaged up to passage $\mathrm{P} 30$ and the experiments were performed between P20 and P30.

\section{shRNA, transfection and lentivirus production}

Experiments of RNA interference are carried out using Mission Lentivirus-based shRNA for PDGFR $\alpha$ (NM_006206-Sigma-Adrich) and PKCa (NM_002737.2Sigma-Aldrich) as reported previously [24]. We selected several puromycin resistant PDGFR $\alpha$-directed shRNA cell clones (shPDGFR $\alpha$-CSC cl.1, 3), but only two significantly targeted PDGFR $\alpha$ expression (TRCN0000195132/ clone 1 and TRCN0000196928/clone 3. Similarly, we selected GBM CSC clones expressing shRNA for PKC $\alpha$ (TRCN0000233511 and TRCN0000233513).

\section{Western blots}

GBM CSC are seeded as single cells $\left(1 \times 10^{6} / \mathrm{p} 90\right.$ dish) in proliferation medium, and collected 2-3 days later for Western blot analysis. Afterwards, cells were collected and washed with PBS containing proteases inhibitors before protein extraction in $100-150 \mu$ of lysis buffer (1\% NP-40, 0.01\% SDS, $20 \mathrm{mM}$ Tris- $\mathrm{HCl}$ $\mathrm{pH}$ 7.4, $300 \mathrm{mM} \mathrm{NaCl}, 1 \mathrm{mM}$ EDTA, $1 \mathrm{mM} \mathrm{Na} 3 \mathrm{VO} 4$ and protease inhibitors cocktail from Sigma-Aldrich). 
Then, cells were sonicated with two pulses of $5 \mathrm{sec}$ at $50 \%$ of amplitude (Sonics and Materials, Newtown, CT). Equal amounts $(30 \mu \mathrm{g} / \mathrm{lane})$ of total protein extracts, quantified by Bio-Rad protein Assay (Bio-Rad, Munchen, Germany), were loaded on PAGE Bis-Tris gels (FISHER), and transferred on Hybond-P Extra membrane (Amersham Biosciences, GE Healthcare Life ScienceBuckinghamshire, UK). Filters were immunoblotted using the following primary antibodies: rabbit antiEGFR, rabbit anti-Y1068-EGFR, goat anti-PDGFR $\alpha$, rabbit anti-T202/Y204-ERK1/2 and anti-ERK1/2, rabbit anti-Y705-STAT3 and rabbit anti-STAT3, rabbit anti-T638/641-PKC $\alpha / \beta I I$, rabbit anti-PCK $\alpha$, rabbit antiVEGFR2 (all purchased from Cell Signaling, MA-USA), mouse anti-underphosphorylated Rb1 (BD Pharmigen), Rabbit anti-Rb1 (Cell Signaling), mouse anti-BCL-2 (Dako), mouse anti-Nestin (Millipore), mouse antiGFAP (Covance), rabbit anti-NG2 (Chemicon), mouse anti-MAP2a/b and rabbit anti-OCT4 (Millipore), rabbit anti-BCL-X/L, rabbit anti-CycD1, rabbit anti-SOX2, rabbit anti-BMI1 and rabbit anti-EGR1, rabbit antiCD31, goat anti-VE-Cadherin (Santa Cruz-USA), mouse anti- $\beta$-actin (SIGMA). After three washing with TBS-Tween buffer, immuno-reactive proteins were detected using rabbit anti-mouse, donkey-anti-rabbit and donkey anti-goat horseradish peroxidase-conjugated secondary antibodies directed to the appropriate primary antibodies (Jackson Immunoresearch Laboratories, West Grove, PA). The proteins were then visualized using the chemiluminescence system (Millipore). Gels and images acquisition were done by HP Photosmart Essential Ver. 1.12 and Adobe Photoshop CS5 respectively. The densitometric analysis of protein bands normalized against to $\beta$-actin protein levels was performed from two independent experiments using the ImageJ software (NIH, USA).

\section{Cell proliferation, differentiation and pharmacological treatment of GBM CSC}

To monitor neurospheres formation of shPDGFR $\alpha$ CSC vs control cells (pLKO.1), cells are dissociated into single cells and $1 \times 10^{4}$ cells/well were plated in triplicate on 6-well dishes. Cells are imaged in phase-contrast after 3 and 7 day in growth medium using an Olympus CX41 microscope with $20 \mathrm{X} / 10 \mathrm{X}$ objectives. For cell differentiation, cells were dissociated in single cells and plated onto matrigel-coated $100 \mathrm{~mm}$ dishes in presence of $5 \%$ fetal calf serum (FCS) for 1, 2 and 4 days. To assess the effects of pharmacological treatments, time course experiments were conducted on cells undergone to growth factors withdrawal for 2 days and then stimulated with exogenous PDGF-AA (Peprotech) alone or combined with $10 \mu \mathrm{M}$ of Crenolanib (CP-868,596; Selleckchem), for different time points (5-10-30-120 minutes until 24 hours).

\section{RT-qPCR assay}

Total RNA was extracted using Triazol and by RNeasy mini kit (Qiagen, USA). cDNAs were obtained using QuantiTect Reverse Transcription kit (Qiagen, USA). Quantitative Real Time Reverse Transcriptase PCR (RT-qPCR) was conducted in triplicate using SYBR Hi-ROX kit (Bioline, UK). RT-qPCR was performed with a 7900HT instrument equipped with SDS2.2 software (Applied Biosystems, CA). The sequences of oligonucleotides used for RT-qPCR were described in Table 1. The Fold change (Fc) were obtained by normalization of RNAs expression respect to selected housekeeper genes (GAPDH, TBP) and respect to pLKO.1 cells.

\section{Cell invasion assay}

For the invasion assay, $1 \times 10^{5}$ cells resuspended in $0.3 \mathrm{ml}$ of Stem Medium and placed in triplicate into the top chamber of $150 \mu 1$ matrigel-coated transwell insert (Millipore). The bottom wells contained $0.4 \mathrm{ml}$ of stem medium as control or stem medium with PDGFAA or EGF $(50 \mathrm{ng} / \mathrm{ml})$ as chemoattractant. After $48 \mathrm{~h}$, cells on the top surface of the filter are removed with a cottonswab. Thereafter, the filters are fixed and stained with $0.5 \%$ of crystal violet and subsequently washed to collect the staining solution. OD values, proportional to the number of cells, are measured by a plate reader at $590 \mathrm{~nm}$ (Bio-Rad). These experiments were performed twice and each time in triplicate. The absorbance values were calculated as mean $\pm \operatorname{SD}(n=3)$ of two different experiments.

\section{Statistical analysis}

Statistical analysis was performed with Prism5 (GraphPad) and Microsoft Office Excel 2013. All data shown are representative of results obtained from two independent experiments conducted in triplicate. The results were analyzed by Two-way ANOVA and Bonferroni's post tests. Data are expressed as mean \pm SD $(n=3)$ of 2 independent experiments, and $\mathrm{P}$ values $\leq 0.05$ $(*), \leq 0.01(* *), \leq 0.001(* * *)$ were considered statistically significant.

\section{ACKNOWLEDGMENTS}

This work was supported by the Italian Ministry for Education, University and Research (MIUR), FIRB 2010-Accordi di Programma, Project n. RBAP10KJC5. This work is dedicated to my father, Sergio Cenciarelli. 
Table 1: List of primers for RT-PCR analysis

\begin{tabular}{|c|c|c|c|}
\hline Gene ID & Name & & Sequences $5^{\prime} \rightarrow 3^{\prime}$ \\
\hline \multirow[t]{2}{*}{ NM_001128128.2 } & hZEB1 & For & ATGACCTGCCAACAGACCAG \\
\hline & & Rev & TTGCCCTTCCTTTCCTGTGT \\
\hline \multirow[t]{2}{*}{ NM_001171653.1 } & hZEB2 & For & AAGCCTCTGTAGATGGTCCAG \\
\hline & & Rev & GTCACTGCGCTGAAGGTACT \\
\hline \multirow[t]{2}{*}{ NM_003380.3 } & hVIM & For & AGAGGAAGCCGAAAACACCC \\
\hline & & Rev & TCAAGGTCAAGACGTGCCAG \\
\hline \multirow[t]{2}{*}{ NM_000474.3 } & hTWIST & For & TCAAGAGGTCGTGCCAATCA \\
\hline & & Rev & ATGGTTTTGCAGGCCAGTTT \\
\hline \multirow[t]{2}{*}{ NM_001166055.1 } & hEDNRA & For & GAGGTTTTCTGAAGCCGGGG \\
\hline & & Rev & TGTGCTGCTTTTACACCTTCAC \\
\hline \multirow[t]{2}{*}{ NM_000115.3 } & hEDNRB & For & TGCTTGCTTCATCCCGTTCA \\
\hline & & Rev & GGCCAATGGCAAGCAGAAAT \\
\hline \multirow[t]{2}{*}{ NM_001168319.1 } & hEDN1 & For & TGAGAGGAAGAAAAATCAGAAGA \\
\hline & & Rev & TTTCTCATGGTCTCCGACCT \\
\hline \multirow[t]{2}{*}{ NM_001306132.1 } & hFN1 & For & TGACAAGCAGACCAGCTCAG \\
\hline & & Rev & CTGTCACACGAGCCCTTCTT \\
\hline \multirow[t]{2}{*}{ NM_001795.3 } & hCDH5 & For & ATGCGGCTAGGCATAGCATT \\
\hline & & Rev & TGTGACTCGGAAGAACTGGC \\
\hline \multirow[t]{2}{*}{ NM_004360.3 } & hCDH1 & For & CGAGAGCTACACGTTCACGG \\
\hline & & Rev & CTTTGTCGACCGGTGCAATC \\
\hline \multirow[t]{2}{*}{ NM_000442.4 } & hPECAM1 & For & TGATGCCGTGGAAAGCAGAT \\
\hline & & Rev & GCATCTGGCCTTGCTGTCTA \\
\hline \multirow[t]{2}{*}{ NM_002253.2 } & hVEGFR2 & For & ACAGCAACTTGCAGGACAGT \\
\hline & & Rev & GAGCTCGATGCTCACTGTGT \\
\hline \multirow[t]{2}{*}{ NM_003106.3 } & hSOX2 & For & AATAGCATGGCGAGCGGGG \\
\hline & & Rev & CCGTTCATGTGCGCGTAACT \\
\hline \multirow[t]{2}{*}{ NM_001173531.2 } & hOCT4 & For & CTCGAGAAGGATGTGGTCCG \\
\hline & & Rev & TAGTCGCTGCTTGATCGCTT \\
\hline \multirow[t]{2}{*}{ NM_000321.2 } & hRB1 & For & CTCACCTCCCATGTTGCTCA \\
\hline & & Rev & GGGTGTTCGAGGTGAACCAT \\
\hline \multirow[t]{2}{*}{ NM_002737.2 } & hPRKCA & For & ATATGTCAACGGTGGGGACC \\
\hline & & Rev & TCCGATGGAAATCTCTGCCG \\
\hline \multirow[t]{2}{*}{ NM_002738.6 } & hPRKCB1 & For & TCCAGCCCCCTTATAAGCCA \\
\hline & & Rev & GATGGCGGGTGAAAAATCGG \\
\hline \multirow[t]{2}{*}{ NM_033023.4 } & hPDGFA & For & CGGATACCTCGCCCATGTTC \\
\hline & & Rev & CGGATGCTGTGGATCTGACT \\
\hline NM_033016.2 & hPDGFB & For & GGTGAGATGTTTATCATGGGCCT \\
\hline
\end{tabular}

(Continued) 


\begin{tabular}{llll}
\hline Gene ID & Name & & Sequences $\mathbf{5} \rightarrow \mathbf{3}$ \\
\hline \multirow{2}{*}{ NM_016205.2 } & & Rev & CGAGTGGTCACTCAGCATCT \\
& hPDGFC & For & TCTGAACCAGGGTTCTGCATC \\
NM_025208.4 & hPDGFD & Fev & AAGGGGGTAGCACTGAAGGA \\
& & Rev & TCGGTATCGAGGCAGGTCAT \\
NM_031847.2 & hMAP2 & For & GCTCTGGCTCCCAGTGTATT \\
& & Rev & GAGCGCTTTTCTGGGCTCTT \\
NM_001172085.1 & hTBP & For & GAACATCATGGATCAGAACAACA \\
& & Rev & ATAGGGATTCCGGGAGTCAT \\
NM_001256799.2 & hGAPDH & For & AGCCACATCGCTCAGACA \\
& & Rev & GCCCAATACGACCAAATCC \\
\hline
\end{tabular}

\section{CONFLICTS OF INTEREST} interest

The authors declare that they have no conflicts of

\section{REFERENCES}

1. De la Iglesia N, Puram SV, Bonni A. STAT3 regulation of glioblastoma pathogenesis. Curr Mol Med. 2009; 9:580-590.

2. Fleming TP, Saxena A, Clark WC, Robertson JT, Oldfield EH, Aaronson SA, Ali IU. Amplification and/or overexpression of platelet-derived growth factor receptors and epidermal growth factor receptor in human glial tumors. Cancer Res. 1992; 52:4550-3.

3. Brennan C, Momota H, Hambardzumyan D, Ozawa T, Tandon A, Pedraza A, Holland E. Glioblastoma subclasses can be defined by activity among signal transduction pathway and associated genomic alterations. PLoS ONE. 2009; Vol. 4, issue 11, e7752.

4. Le Mercier M, Hastir D, Moles Lopez X, De Neve N, Maris C, Trepant AL, Rorive S, Decaestecker C, Salmon I. A Simplified Approach for the Molecular Classification of Glioblastomas. PLoS ONE. 2012; 20 Vol. 7:e45475.

5. Heldin $\mathrm{CH}$. Targeting the PDGF signaling pathway in tumor treatment. Cell Comm. and Signal. 2013, 11:97.

6. Shih AH, Holland EC. Platelet-derived growth factor (PDGF) and glial tumorigenesis. Cancer Lett. 2006; 232:139-47.

7. Kim Y, Kim E, Wu Q, Guryanova O, Hitomi M, Lathia JD, Serwanski D, Sloan AE, Weil RJ, Lee J, Nishiyama A, Bao S, Hjelmeland AB, Rich JN. Platelet-derived growth factor receptors differentially inform intertumoral and intratumoral heterogeneity. Genes Dev. 2012; 26:1247-62.
8. Sathornsumetee S, Rich JN. Antiangiogenic therapy in malignant glioma: promise and challenge. Curr Pharm Des. 2007; 13:3545-58.

9. Navis AC, Hamans BC, Claes A, Heerschap A, Jeuken JW, Wesseling P, Leenders WP. Effects of targeting the VEGF and PDGF pathways in diffuse orthotopic glioma models. $\mathrm{J}$ Pathol. 2011; 223:626-34.

10. Puram SV, Yeung CM, Jahani-Asl A, Lin C, de la Iglesia N, Konopka G, Jackson-Grusby L, Bonni A. STAT3-iNOS Signaling Mediates EGFRvIII-Induced Glial Proliferation and Transformation. J Neurosci. 2012; 32:7806-18.

11. Bonni, A, Sun Y, Nadal-Vicens M, Bhatt A, Frank DA, Rozovsky I, Stahl N, Yancopoulos GD, and Greenberg ME. Regulation of gliogenesis in the central nervous system by the JAK-STAT signaling pathway. Science. 1997; 278:477-483.

12. Cao F, Hata R, Zhu P, Nakashiro K, Sakanaka M. Conditional Deletion of STAT3 induces neurogenesis and inhibits astrogliogenesis in neural stem cells. Bioch. Biophis. Com. Res. 2010; 394:843-847.

13. Sherry MM, Reeves A, Wu JK, Cochran BH. Stat3 is required for proliferation and maintenance of multipotency in glioblastoma Stem Cells. Stem Cells. 2009;:2383-92.

14. Benzil DL, Finkelstein SD, Epstein MH, Finch PW. Expression pattern of alpha-protein kinase $\mathrm{C}$ in human astrocytomas indicates a role in malignant progression. Cancer Res.1992; 52, 2951-2956.

15. Kang JH, Mori T, Kitazaki H, Niidome T, Takayama K, Nakanishi Y, Katayama Y. Serum protein kinase $\mathrm{C} \alpha$ as a diagnostic biomarker of cancers. Cancer Biomark. 2013; 13:99-103.

16. Lin CW, Shen SC, Chien CC, Yang LY, Shia LT, Chen YC. 12-O-tetradecanoylphorbol-13-acetate-induced invasion/migration of glioblastoma cells through activating PKCalpha/ERK/NF-kappaB-dependent MMP-9 expression. J Cell Physiol. 2010; 225:472-81. 
17. Qin L, Yin YT, Zheng FJ, Peng LX, Yang CF, Bao YN, Liang YY, Li XJ, Xiang YQ, Sun R, Li AH, Zou RH, Pei XQ, Huang BJ, Kang TB, Liao DF, Zeng YX, Williams BO, Qian CN. WNT5A promotes stemness characteristics in nasopharyngeal carcinoma cells leading to metastasis and tumorigenesis. Oncotarget. 2015; 6:10239-52. doi: 10.18632/oncotarget.3518.

18. Saito Y, Haendeler J, Hojo Y, Yamamoto K, Berk BC. Receptor heterodimerization: essential mechanism for platelet-derived growth factor-induced epidermal growth factor receptor transactivation. Mol Cell Biol. 2001; 21:6387-94.

19. Indovina P, Pentimalli F, Casini N, Vocca I, Giordano A. RB1 dual role in proliferation and apoptosis: Cell fate control and implications for cancer therapy. Oncotarget. 2015; 6:17873-9. doi: 10.18632/oncotarget.4286.

20. Harbour JW, Luo RX, Dei Santi A, Postigo AA, Dean DC. Cdk phosphorylation triggers sequential intramolecular interactions that progressively block $\mathrm{Rb}$ functions as cells move through G1. Cell. 1999; 98:859-69.

21. Baldin V, Lukas J, Marcote MJ, Pagano M, Draetta G. Cyclin D1 is a nuclear protein required for cell cycle progression in G1. Genes Dev.1993; 7:812-21.

22. Schröder LBW and McDonald KL. CDK4/6 Inhibitor PD0332991 in Glioblastoma Treatment: Does It Have a Future? Front Oncol. 2015; 30; 5:259.

23. Cenciarelli C, Marei HE, Zonfrillo M, Pierimarchi P, Paldino E, Casalbore P, Felsani A, Vescovi AL, Maira G, Mangiola A. PDGF receptor alpha inhibition induces apoptosis in glioblastoma cancer stem cells refractory to anti-Notch and anti-EGFR treatment. Mol Cancer. 2014; 13:247.

24. Piccirillo SG, Combi R, Cajola L, Patrizi A, Redaelli S, Bentivegna A, Baronchelli S, Maira G, Pollo B, Mangiola $\mathrm{A}$, DiMeco F, Dalprà L, Vescovi AL. Distinct pools of cancer stem-like cells coexist within human glioblastomas and display different tumorigenicity and independent genomic evolution. Oncogene. 2009; 28:1807-11.

25. Frixen UH, Behrens J, Sachs M, Eberle G, Voss B, Warda A, Löchner D, Birchmeier W. E-cadherin-mediated cell-cell adhesion prevents invasiveness of human carcinoma cells. J Cell Biol. 1991; 113:173-185.

26. Huang L, Fu L. Mechanisms of resistance to EGFR tyrosine kinase inhibitors. Acta Pharm Sin B. 2015; 5:390-401.

27. Nishiyama A, Lin XH, Giese N, Heldin CH, Stallcup WB. Interaction between NG2 proteoglycan and PDGF alphareceptor on $\mathrm{O} 2 \mathrm{~A}$ progenitor cells is required for optimal response to PDGF. J Neurosci Res. 1996; 43:315-30.

28. Sakakini N, Turchi L, Bergon A, Holota H, Rekima S, Lopez F, Paquis P, Almairac F, Fontaine D, Baeza-Kallee N, Van Obberghen-Schilling E, Junier MP, Chneiweiss $\mathrm{H}$, Figarella-Branger D, Burel-Vandenbos F, Imbert J, Virolle T. A positive feed-forward loop associating EGR1 and PDGFA promotes proliferation and self-renewal in glioblastoma stem cells. J Biol Chem. 2016; Mar 21. pii: jbc.M116.720698. [Epub ahead of print]

29. Satelli A and Shulin L. Vimentin as a potential molecular target in cancer therapy: an overview and its potential as a molecular target for cancer therapy. Cell Mol Life Sci. 2011; 68:3033-3046.

30. Mikheeva SA, Mikheev AM, Petit A, Beyer R, Oxford RG, Khorasani L, Maxwell JP, Glackin CA, Wakimoto H, González-Herrero I, Sánchez-García I, Silber JR, Horner PJ, Rostomily RC. TWIST1 promotes invasion through mesenchymal change in human glioblastoma. Mol. Cancer. 2010; 194:1-18.

31. Wang Y, Shi J, Chai K, Ying X, Zhou BP. The Role of Snail in EMT and Tumorigenesis Curr Cancer Drug Targets. 2013; 13:963-72.

32. Mazzoleni S, Politi LS, Pala M, Cominelli M, Franzin A, Sergi Sergi L, Falini A, De Palma M, Bulfone A, Poliani PL, Galli R. Epidermal Growth Factor Receptor Expression Identifies Functionally and Molecularly Distinct TumorInitiating Cells in Human Glioblastoma Multiforme and Is Required for Gliomagenesis. Cancer Res. 2010, 19:7500-7513.

33. Liu Y, Ye F, Yamada K, Tso JL, Zhang Y, Nguyen DH, Dong Q, Soto H, Choe J, Dembo A, Wheeler H, Eskin A, Schmid I, Yong WH, Mischel PS, Cloughesy TF, Kornblum HI, Nelson SF, Liau LM, Tso CL. Autocrine endothelin-3/ endothelin $\mathrm{B}$ receptor signaling maintains cellular and molecular properties of glioblastoma stem cell. Mol Cancer Res. 2011; 9:1668-1685.

34. Kim SJ, Lee HJ, Kim MS, Choi HJ, He J1, Wu Q, Aldape K, Weinberg JS, Yung WK, Conrad CA, Langley RR, Lehembre F, Regenass U, Fidler IJ. Macitentan, in Dual Endothelin Receptor Antagonist in Combination with Temozolomide Leads to Glioblastoma Regression and Long-term Survival in Mice. Clin Cancer Res. 2015; 21:4630-41.

35. Di Tomaso E, London N, Fuja D, Logie J, Tyrrell JA, Kamoun W, Munn LL, Jain RK. PDGF-C induces maturation of blood vessels in a model of glioblastoma and attenuates the response to anti-VEGF treatment. PLoS One. 2009; 4:e5123.

36. Karpel-Massler G, Bâ M, Shu C, Halatsch ME, Westhoff MA, Bruce JN, Canoll P, Siegelin MD.TIC10/ONC201 synergizes with $\mathrm{Bcl}-2 / \mathrm{Bcl}-\mathrm{xL}$ inhibition in glioblastoma by suppression of Mcl-1 and its binding partners in vitro and in vivo. Oncotarget. 2015; 6:36456-71. doi: 10.18632/ oncotarget.5505.

37. Rosanò L, Spinella F, Bagnato A. Endothelin 1 in cancer: biological implications and therapeutic opportunities. Nat Rev Cancer. 2013; 13:637-51.

38. Dong Y, Jia L, Wang X, Tan X, Xu J, Deng Z, Jiang T, Rainov NG, Li B, Ren H. Selective inhibition of PDGFR by imatinib elicits the sustained activation of ERK and downstream receptor signaling in malignant glioma cells. Int J Oncol. 2011; 38:555-69. 
39. Lokker NA, Sullivan CM, Hollenbach SJ, Israel MA, Giese NA. Platelet derived growth factor (PDGF) autocrine signaling regulates survival and mitogenic pathways in glioblastoma cells: evidence that the novel PDGF-C and PDGF-D ligands may play a role in the development of brain tumors. Cancer Res. 2002; 62:3729-3735.

40. Tam WL, Lu H, Buikhuisen J, Soh BS, Lim E, Reinhardt F, Wu ZJ, Krall JA, Bierie B, Guo W, Chen X, Liu XS, Brown M, Lim B, Weinberg RA. Protein kinase $\mathrm{C} \alpha$ is a central signaling node and therapeutic target for breast cancer stem cells. Cancer Cell. 2013; 24:347-364.

41. do Carmo A, Balça-Silva J, Matias D, Lopes MC. PKC signaling in glioblastoma. Cancer Biol Ther. 2013; 14:287-94.

42. Misra-Press, AP, Fields, Samols D, and Goldthwait DA. Protein kinase $\mathrm{C}$ isoforms in human glioblastoma cells. Glia. 1992; 6:188-197.

43. Wick W, Puduvalli VK, Chamberlain MC, van den Bent MJ, Carpentier AF, Cher LM, Mason W, Weller M, Hong S, Musib L, Liepa AM, Thornton DE, Fine HA. Phase III Study of Enzastaurin Compared With Lomustine in the Treatment of Recurrent Glioblastoma Intracranial, J Clin Oncol. 2010; 28:1168-1174.

44. Carducci MA, Musib L, Kies MS, Pili R, Truong M, Brahmer JR, Cole P, Sullivan R, Riddle J, Schmidt J, Enas N, Sinha V, Thornton DE, Herbst RS. Phase I dose escalation and pharmacokinetic study of enzastaurin, an oral protein kinase $\mathrm{C}$ beta inhibitor, in patients with advanced cancer. J Clin Oncol. 2006; 24:4092-99.

45. Pilkington GJ. Cancer stem cells in the mammalian central nervous system. Cell Prolif. 2005; 38:423-33.

46. Chekenya M, Hjelstuen M, Enger PØ, Thorsen F, Jacob AL, Probst B, Haraldseth O, Pilkington G, Butt A, Levine JM, Bjerkvig R. NG2 proteoglycan promotes angiogenesis-dependent tumor growth in CNS by sequestering angiostatin. FASEB J. 2002;16:586-8.

47. Ichimura K, Schmidt EE, Goike HM, Collins VP. Human glioblastomas with no alterations of the CDKN2A (p16INK4A, MTS1) and CDK4 genes have frequent mutations of the retinoblastoma gene. Oncogene. 1996; 13:1065-72.

48. Michaud K, Solomon DA, Oermann E, Kim JS, Zhong WZ, Prados MD, Ozawa T, James CD, Waldman T. Pharmacologic inhibition of cyclin-dependent kinases 4 and 6 arrests the growth of glioblastoma multiforme intracranial xenografts. Cancer Res. 2010; 70:3228-38.

49. Ziegler DS, Wright RD, Kesari S, Lemieux ME, Tran MA, Jain M, Zawel L, Kung AL Resistance of human glioblastoma multiforme cells to growth factor inhibitors is overcome by blockade of inhibitor of apoptosis proteins. $\mathrm{J}$ Clin Invest. 2008; 118:3109-22.

50. Ichimura K, Bolin MB, Goike HM, Schmidt EE, Moshref A, Collins VP. Deregulation of the p14ARF/MDM2/p53 pathway is a prerequisite for human astrocytic gliomas with G1-S transition control gene abnormalities. Cancer Res. 2000;60:417-24.

51. Johnson J, Thijssen B, McDermott U, Garnett M, Wessels LF, Bernards R. Targeting the RB-E2F pathway in breast cancer. Oncogene. 2016; Feb 29. doi: 10.1038/onc.2016.32. [Epub ahead of print].

52. Biasoli D, Kahn SA, Cornelio TA, Furtado M, Campanati L, Chneiweiss H, Moura-Neto V and Borges HL. Retinoblastoma protein regulates the crosstalk between autophagy and apoptosis, and favors glioblastoma resistance to etoposide. Cell Death and Disease. 2013; 4, e767.

53. Nakamura M, Yonekawa $\mathrm{Y}$, Kleihues $\mathrm{P}$, Ohgaki H. Promoter hypermethylation of the RB1 gene in glioblastomas. Lab Invest. 2001; 81:77-82. 